\title{
Martins Pena encenador: uma reviravolta na fortuna crítica
}

\author{
Luis Fernando Ramos \\ Universidade de São Paulo
}

A bibliografia existente sobre a vida e a obra de Martins Pena remonta ao século dezenove. Em 1877, Luiz Francisco da Veiga deu-se ao trabalho de realizar um paciente e precioso trabalho de levantamento, através do Jornal do Comércio, de todas as notícias publicadas acerca da publicação e representação das peças do dramaturgo no Rio de Janeiro entre 1837 e $1847 .{ }^{1}$ Foi graças a este levantamento minucioso que biógrafos posteriores, como Raimundo Magalhães Jr. e Darcy Damasceno, puderam fixar o conjunto da obra de Pena com precisão. Talvez porque Luiz Francisco da Veiga não fosse um intelectual preocupado com as questões estéticas, mas simplesmente um estudioso dedicado à preservação da memória de um grande brasileiro, seu estudo passe hoje quase despercebido diante de diversos comentadores que, de pontos de vista mais elevados, procuraram descrever e interpretar o fenômeno Martins Pena. Porém, para uma pesquisa preocupada em rever a historiografia na perspectiva da encenação, e investigar as circunstâncias em que Martins Pena teve, entre 1838 e 1846, dezoito de suas peças encenadas no Teatro São Pedro, o trabalho de Veiga situa-se entre os mais valiosos.

A biografia de Veiga revela, por exemplo, a importância da amizade de Pena com o chamado "inspector da scena" do Teatro São Pedro, José Antônio Thomaz Romeiro, para que o jovem dramaturgo concretizasse no palco do principal teatro da corte tantas montagens, incluindo a encenação de um de seus dramas, Vitiza, ou o Nero de Espanha. É, alias, na relação entre este drama e o citado "inspector da scena" que se pinça outra descoberta preciosa de Veiga: o comentário anônimo, em comunicado fora da coluna "Theatros" do Jornal do Comércio, no dia 15 de setembro de 1845, elogiando o esmero do "Sr. Romeiro" nos preparativos para a estréia do único drama de Martins Pena encenado.

Consta-nos que se acha em ensaios e que brevemente subirá à scena no theatro de S.Pedro, um drama original em 5 actos e em verso, pelo autor das Comédias O Noviço, o Inglês Maquinista, Irmão das Almas, etc. Esse drama que se intitula - Vitiza, ou o Nero de Hespanha, é extraído 
das crônicas hespanholas do tempo dos reis Godos. Affirmão-nos que o Sr. Romeiro, inspector de scena, desvela-se em que o drama suba à representação como todo o primor e pompa, e que assim dirigido fará grande effeito em scena, tanto pelo interesse e vivacidade da intriga, como pelo apparato de todos os seus actos. Ansiosos esperamos pela noite da representação e sem dúvida o público acostumado a rir-se com as graciosas comédias do mesmo autor nos acompanhará nesse desejo curioso de ver como escreve ele o gênero trágico. É sem dúvida digna de louvor a diretoria do theatro de S. Pedro por animar e proteger a escriptores nacionais. Só assim teremos um theatro brasileiro; e a nosso ver esse é o mais valioso documento que a diretoria pode exibir, quando requer ao corpo legislativo loterias para manutenção do theatro nacional. ${ }^{2}$

Este comentário é a prova mais eloqüente para qualificar a pretensão de se ver neste “inspector de scena' não só um proto-encenador, mas, também, especificamente no caso do Sr. Romeiro, um personagem decisivo na concretização do projeto teatral de Martins Pena. Permite também alimentar a hipótese, já aventada, em torno da importância que o chamado "pai da comédia nacional" dava a seus dramas, e de como eles podem ser vistos como ensaios para uma ambição mais alta, e nada secreta, de concretizar uma ópera brasileira. A expectativa do comentarista sobre a estréia da primeira peça séria do já, àquela altura, conhecido comediógrafo, ilustra a importância que Pena e ele próprio, o redator da coluna "Theatros", atribuem ao evento. Num procedimento absolutamente extraordinário em relação às colunas diárias habituais, o Jornal do Comércio publica no dia 21 de setembro de 1845, data da estréia do espetáculo, além da notícia, propriamente, um caudaloso comentário municiando o público de dados para fruir a estréia do texto de Pena.

O vestuário é inteiramente novo, e a representação será enriquecida de todo o apparato necessário. Parte histórica do drama-Não se descuidou Vitiza de passar à luzitãnia, imediatamente depois de estar associado na coroa, e pôr a sua corte na cidade de Braga. Tinha gênio ardente e impetuoso, e contudo soube recatar a inclinação que o arrastara ao vício todo o tempo que seu pai viveu; mas uma vez que com a morte de Egica se vio senhor absoluto do throno, ofuror das paixões que até 
então estiverão represadas, o levarão de rojo rapidamente aos mais vergonhosos excessos de devassidão, e deu-se a eles tão soltamente, sendo tão feios os seus vícios, que lhe puserão por appelido o Nero de Hespanha. Entre suas fúrias foi a primeira de querer arrazar todas as fortificações e muralhas das cidades, assentando que com este expediente estornava todos os meio de rebelliões, sem ponderar que com ofim de precaver um mal incerto, se aventurava a outro mais certo, deixando o reino sem se poder defender desde fora.... Vitiza assim requintou a sua lascívia que casou com muitas mulheres ao mesmo tempo, e permithiu aos seus vassalos seguir-lhe o exemplo. Assentou Vitiza que lhe seria útil tornarem à Hespanha os judeus, e dar-lhes maiores privilégios ainda de que gozavão os critãos. Mandou vasar os olhos de Theodoredo, filho ou irmão de Rescencindo, como também a Favilla, que matou passado pouco tempo, affim de gosar de uma sua parenta, a quem tinha um amor desatinado. Tinha Theodofredo um filho por nome Roderigo e Favila tinha outro também chamado Pelagio....Vitiza geralmente aborrecido de todos os seus súbditos, Roderigo, que no princípio se tinha escondido aos seus furores, estimulado da barbaridade praticada com seu pai, se fez cabeça de alguns decontentamentos e arejou o throno o abominável Vitiza. Foi Roderigo o último dos reis Godos (Hist. De Portug. Por M. de la Clede). ${ }^{3}$

A profusão dos detalhes, na apresentação do embasamento histórico de que partiu Martin Pena em seu drama, é expressiva. Com essa combinação de programa sintético de libreto de ópera e documento histórico, o redator do Jornal do Comércio não deixa dúvidas sobre a importância de que reveste aquela estréia. Essa relevância é destacada por Luiz Francisco da Veiga quando, na terceira parte de sua biografia, tece alguns pouco comentários sobre os aspectos estéticos da produção de Pena.

(...) o excellente acolhimento que mereceu do publico fluminense o drama em verso, em cinco atos e um prólogo, denominado Witiza ou o Nero de Hespanha, seus judiciosos e picantes folhetins, em uma importante folha diária d'esta corte, e o romance histórico que escreveu, 
provam que o talento de Luiz Penna não era harpa de uma só corda, que modulasse uma eterna monodia, que não tinha elle por único campo de actividade e único de estádio de gloria, a ridente e iriada comedia, com seus fogos de artifício cambiantes, e sua plethora e convulsão de hilariedade, de sarcasmo e de ridiculo; mas pelo contrario, que tal talento era multiforme e omnimodo, capaz dos mais arrojados e variados commetimentos literários opulentamente apto para cultivar, com feliz êxito, todos os gêneros de literatura. ${ }^{4}$

A leitura favorável de Luiz Francisco da Veiga a Vitiza ou o Nero de Eespanha, não foi confirmada nem pelos contemporâneos de Martins Pena - não existe registro, à época, de qualquer crítica posterior ao espetáculo - nem pela posteridade. Todos os comentadores seguintes, a começar de Sílvio Romero e José Veríssimo até Décio de Almeida Prado, foram unânimes em desqualificar os dramas trágicos de Pena, incluindo Vitiza ou o Nero de Eespanha, tachandoos como ruins dramaticamente e sem nenhum valor literário. Para a pesquisa dos aspectos cênicos e materiais do teatro de Pena, no entanto, o levantamento iniciado por Da Veiga torna-se muito mais proveitoso que as acerbas críticas de historiadores mais ilustres. Até porque, do ponto de vista da história do espetáculo, não importa tanto a superior qualidade dramática e literária dos textos quanto as informações disponíveis sobre a teatralidade do período e, nesse aspecto, os dramas, seja pelo que indicam nas rubricas, seja por dados objetivos como o tratamento que receberam na estréia citada, são muito mais ricos que as comédias. Acrescente-se a preocupação de Pena, manifesta nos Folhetins que escreveria entre 1846 e 1847, de criar uma ópera brasileira e fazer dos textos dos dramas - em versos no caso de Vitiza ou Nero de Eespanha - ensaios de futuros libretos.

Outro crítico cuja leitura da obra de Pena ilumina essa perspectiva da reconstituição das condições materiais é Raimundo Magalhães Jr, cuja biografia-Martins Pena e sua época ${ }^{5}$ - pode ser considerada a mais completa e informativa existente. Magalhães Jr, partilha com outros críticos as restrições aos dramas de Pena, mas não deixa de dedicar um capítulo a eles e fornece dados interessantes a respeito da investigação histórica em torno dos personagens utilizados em Vitiza ou Nero de Hespanha, tentando demonstrar como a fonte em que Pena se baseou não merece muito crédito. Segundo Magalhães $\mathrm{Jr}$, a peça foi representada, além da estréia, no dia 21 de setembro de 1845 , 
mais uma vez na terça-feira dia 23. Mesmo não acrescentando muito a essa informação, Magalhães Jr não despreza o significado de estrear-se um drama no Teatro São Pedro, naquele momento histórico e cultural. Em capítulo sobre o "poeta Martins Pena" ele defende a tese de que Pena teria se inspirado nos dramas em verso de Gonçalves de Magalhães, e na expectativa de atender aos reclamos de João Caetano por um drama nacional. A despeito da pertinência desta opinião, irrelevante do ponto de vista aqui enfatizado, Magalhães Jr reforça a hipótese de que ao fazer dramas Pena revelava uma ambição de espetáculos mais sofisticados, o que confirmaria a hipótese que os dramas foram ensaios no desenvolvimento de uma futura ópera brasileira. Ele reconhece que Pena teve seu nome citado, pela primeira vez, nos anúncios do Jornal do Comércio, só na estréia de Vitiza ou Nero de Hespanha, o que expressa o desprezo a que as comédias eram submetidas na época, e pontua o fato da montagem ter exigido seis cenários distintos na sua produção. Nesse sentido, comentando em capítulo específico sobre os dramas de Pena, justifica as dificuldades que Pena teria tido para levar à cena outro de seus dramas, D. João de Lira ou o Repto, com o argumento que a montagem exigiria "cerca de trinta personagens e cinco diferentes cenários". ${ }^{6}$

Mas é nos comentários sobre as comédias que Raimundo Magalhães Jr dá as contribuições mais positivas para uma investigação voltada para os aspectos cênicos do teatro de Martins Pena. Quando comenta a primeira estréia de Pena, em 1838, com Juiz de Paz na Roça, observa que sendo uma comédia de quatro quadros, com dois cenários distintos, exigiria repetidas mutações. Salienta, contudo, que "sendo os cenários de papel pintado, isso não representava grande problema, desde que os contra-regras e maquinistas fossem rápidos na troca do escasso mobiliário". ${ }^{7}$ No comentário da comédia, seguinte, A Família e a Festa na Roça, cuja estréia ocorreu em $1^{\circ}$ de setembro de 1840, Magalhães Jr. Oferece uma pista relevante para que o pesquisador dos aspectos visuais dos espetáculos de Martins Pena encontre uma referência objetiva para especular. Trata-se da relação que estabelece entre a última cena de $A$ Família e a Festa na Roça, a que se refere como apêndice indesejável, e as litografias e descrições de festas populares por Jean-Baptiste Debret em seu Viagem Pitoresca e Histórica ao Brasil. Magalhães Jr reconhece na narrativa de Debret, que cita literalmente, a inspiração de Pena para aquela cena final, e compara o texto do artista francês com as rubricas da cena escritas pelo dramaturgo, que revelariam os aspectos visuais da montagem. A observação de Magalhães Jr. pretende, na 
verdade, corroborar a crítica publicada no Jornal do Comércio no dia seguinte à estréia da peça, que aponta a cena do final como supérflua, e não acrescentando nada ao desenvolvimento da trama. Tal crítica, por ser a única existente sobre qualquer uma das montagens de Martins Pena, merece ser citada nos trechos em que sobressaem as censuras com que concorda Magalhães Jr.

(...) Talvez pense o leitor que, com esse desfecho, hum poucochito inverossimil, terminou tudo mas qual! Segue-se a festa do Espírito Santo, o foliões, o coreto de barbeiros, o povo que vem assistir a festa, e o leilão em que por expiação dos pecados dos espectadores, arremata-se um pão de ló, huma galinha, e o cartucho do segredo (...) O Sr Manoel (o ator Manoel Soares) representou mais como um campônio de Portugal do que como um roceiro do Brasil (...) As scenas finaes da festa do espírito Santo forão muito bem caracterizadas: os foliões, os barbeiros, os moços da cidade, as comitivas, tudo realmente he assim; até no povo havia huma tal ou qual semelhança, que o apparecimento de alguns moleques tornaria completa. Mas a que veio tudo isso? Para que todas essas cousas? A função estava acabada, o enredo da peça terminado: que interesse pois podia excitar no espectador toda essa festança? Seria como huma scena de costumes? Ma que relação guardava ella com o enredo da comedia? Em vez de ser collocada no fim da comedia a Festa na Roça não podia ter lugar em outra ocasião qualquer? Antes principiasse a representação pela festa, já que o autor queria descrevê-la por força; antes começassem nela os amores do estudante por Quitéria, ou ai a encontrasse casualmente; enfim por qualquer maneira que fosse pouco importa; era necessário ligá-la à ação principal do drama para não ser considerada uma excrescência escusada. Sendo representada a festa no lugar em que foi, parece que todo o fim do autor foi demonstrar a finura do estudante em rematar um pão de ló para presentear com ele a sua futura espos. ${ }^{8}$

A observação irônica do crítico anônimo do século 19, que Magalhães Jr. reputa "aguda e inteligente", reflete bem um olhar que poderia-se hoje, à luz dos estudos teatrais contemporâneos, ser considerado "textocentrico", no sentido de analisar o espetáculo apenas do ponto de vista literário, do enredo, 
e situar em segundo plano a contribuição dos elementos visuais e materiais da cena. Tanto o crítico do Jornal do Comércio como Magalhães Jr. reconhecem o mérito da reconstituição de uma cena do folclore brasileiro na peça de Pena, mas criticam-no por seu desajuste frente ao enredo principal e pela inexatidão do retrato que realiza. Com isso perdem o que havia, afinal, de mais interessante e original no espetáculo de Pena: a elaboração cênica de um quadro vivo da cultura popular da época, intencionalmente deformado - o imperador não é como a tradição dita um menino, e sim "um homem grande e muito gordo" - mas cheio de exuberância visual. A confirmar esse preconceito da crítica da época, e que está presente na opinião de Magalhães Jr, vale citar ainda o comentário publicado na coluna "Theatros" do Jornal do Comércio, no mesmo dia $1^{\circ}$ de setembro de 1840, bem acima da crítica ao espetáculo de Pena. Trata-se da crítica à estréia, no mesmo teatro São Pedro, do drama Joana de Flandres com produção de João Caetano e tendo como beneficiada Stella Sezefreda, sua companheira. O tom da crítica é semelhante ao utilizado no exame do espetáculo de Martins Penna:

Ainda hontem bradávamos pela representação de peças novas, interessantes, bem distribuídas e devidamente representadas, e hoje já temos de fallar de huma peça nova! E ainda teremos razão de nos queixarmos? Ainda bárbaros, ergueremos a voz contra o mao fado que persegue o Theatro S. Pedro d'Alcãntara? Talvez esperem que nada mais digamos: que, abrindo mão de toda espécie de censura entoemos fervorosos himnos ao impagável theatro, e demos graças a Deos por consentir que assistamos a algumas de suas representações. Com efeito, assim aconteceria, se por ventura em nossa opinião, theatro e marmota fossem synonymos. Se fôramos ao theatro só para gozar de vistas novas, só para abrirmos a boca e deixar cahir o queixo em presença da pompa dos vestuários e da belleza das decorações, bem estava; mas no theatro queremos mais alguma coisa; queremos antes ser impressionados pelos ouvidos do que pelos olhos; preferimos os gozos do coração e da intelligencia aos prazeres da vista, por muito subidos que sejão (...) Os dous primeiros actos são gastos em scenas de muito apparato: no terceiro e quarto he que tem lugar algumas secas que poderião causar interesse, se o caráter de Joana não fosse tão repulsivo (...) Huma das cousas mais notáveis do drama he, sem dúvida alguma, o apparato com que deu a subir à 
scena. A vastidão da sala do theatro de São Pedro a torna muito apropriada para as peças de grande espetáculo: não obstante deixão ellas de produzir entre nós o desejado efeito. Se se trata de apresentar um ajuntamento de povo, he sempre tão minguado, figurarão nelle individuos tão desconformes e apatetados, que parecem só terem por fim o encher número. As cortes são sempre admiráveis, parecem escolhidas a dedo as figuras as mais desengonçadas para darem triste idéia da época que representão (...) No entanto devemos reconhecer que Joana de Flandres subio à scena com mais pompa do que muitos dramas que por ahi andão, e devemos agradecer à beneficiada pelas grandes despezas que fez. Sentimos somente que não fosse mais feliz na escolha. A sra Estella e o Sr. João Caetano estiverão rica e elegantemente vestidos. ${ }^{10}$

Apesar de preferir "os gozos do coração e da inteligência aos prazeres da vista", o crítico do Jornal do Comércio revela também um ressentimento pela pobreza dos resultados - afinal figura-se "indivíduos tão desconformes e apatetados, que parecem só terem por fim o encher número" - e uma admiração e gratidão inegáveis pelo casal de atores. Ou seja, se há uma cegueira para os aspectos espetaculares, no que eles têm de autônomos da ficção literária, não deixa de haver rigor na avaliação de um padrão cênico que as companhias estrangeiras deixavam entrever. No caso de Raimundo Magalhães Jr., quando corrobora a opinião de cunho verista e "textocentrada" do crítico do jornal do Comércio à montagem de Pena, se não percebe a riqueza do espetáculo que o dramaturgo, provavelmente orientado pelo Sr. Romeiro, consegue construir, não deixa de ir mais longe que a maioria dos comentários quando, por exemplo, servindo-se das rubricas da peça, estabelece relações entre estas e as imagens de Debret. ${ }^{11}$

Outro estudioso que contribuiu decisivamente quando se trata, como aqui, de resgatar a materialidade dos espetáculos de Martins Pena, foi Soares Amora. No estudo intitulado Martins Pena e o "Brasil Pitoresco"12 ele bate na mesma tecla de Raimundo Magalhães Jr, ao associar desenhos de Debret e cenas das comédias de Pena. Mas vai mais longe ao incluir em suas observações as gravuras de outros viajantes e estabelecer uma relação direta do "pitoresco" na descrição destes estrangeiros e os elementos característicos das comédias de Pena. Amora lista vários casos de relação direta perceptível entre determinadas 
imagens criadas por estes viajantes e algumas cenas, como estão descritas nas rubricas das comédias de Pena:

Refiro-me, por exemplo, às seguinte cenas da "Família e a Festa na Roça”: chegada da família de Domingos João ao arraial, em carros de bois; a folia do espírito Santo; o leilão de prendas; o lundu-já observadas, no seu lado pitoresco, por Luccock; por Rugendas e por Debret. Refiro-me ainda, e apenas a título de exemplo as seguintes cenas e tipos d'O Juiz de Paz na Roça: o furtivo encontro amoroso de Aninha e José; o jantar da família de Manuel João; o juiz de paz; os soldados da guarda nacional e da Guarda Permanente-cenas e tipos também já observados por Carlos Seidler, por Rugendas e por Debret. Finalmente refiro-me aos seguintes tipos de Um Sertanejo na Côrte: o mineiro qiue chega á Corte; os ciganos; o negociante na Corte - curiosos tipos já surpreendidos pelos comentários e pelo desenho de Rugendas e de Debret. ${ }^{13}$

Amora salienta nesta sua hipótese que Martins Pena conviveu entre os dezoito e os vinte anos, como aluno da Academia de Bellas Artes, com as influências deixadas por Debret ${ }^{14}$, cujo Viagem Pitoresca através do Brasil foi publicado em 1834, quando o jovem escritor tinha 19 anos. Notas Sobre o Rio de Janeiro e Partes Meridionais do Brasil, de John Luccock, tinha sido publicada em 1820, e Viagem Pitoresca e Histórica do Brasil, de Rugendas, e Dez Anos de Brasil, de Carlos Seidler, viriam a público em 1835. Esta sugestão, esboçada em diferentes ângulos por Amora e Magalhães, surge como uma ferramenta na arqueologia que se está propondo no sentido de visualizar a materialidade do teatro de Martins Pena. Seria desejável e deverá ser possível, obter imagens que reportem as cenas dos espetáculos encenados no Teatro São Pedro, seja na forma de gravuras e desenhos, seja enquanto fotografias, pois já havia o daguerreótipo no Rio de Janeiro da década de quarenta do século dezenove. Enquanto elas não surgem, os dados mais objetivos disponíveis são as gravuras e desenhos destes repórteres da vida brasileira sobre o "pitoresco" 15 naquele período. Se forem consideradas como referências espaciais e visuais das cenas que o Pena encenador projetou, são registros suficientes para, no cruzamento com as rubricas das comédias de Pena, formular-se, ainda que virtualmente, uma imagem daquele teatro, ou daquela teatralidade. 
Outros comentadores do teatro de Martins Pena que podem contribuir diretamente nesta investigação são Rugero Jacobi e Darcy Damasceno. O primeiro, num pequeno artigo sobre o comediógrafo relativiza a perspectiva de Martins Pena como um Molière brasileiro e o aproxima mais de Goldoni, principalmente na despretensão estética que percebe na sua abordagem da realidade circundante:

No fundo Martins Pena vai mais além do que um simples artesão, justamente por nada almejar. Não imaginava ele que pudesse haver outra espécie de teatro for do teatro cotidiano. Refaz conscienciosamente as tramas e as e as situações de autores menores (em sua maioria anônimos, ou então franceses ou portugueses da época, algumas vezes adaptados). Não vive entre os livros, mas entre copiões manuscritos, cheios de anotações feitas por empresários, cortes, palavras acrescentadas ou sugeridas pelos atores e anotações dos diretores de cena. A publicação é um destino com que não sonha para suas obras, voltado como está para a representação. Sente-se em todas as suas comédias, o estado fluído da produção teatral, que precede a imaginosa improvisação dos cômicos, e no qual o escrito é apenas uma indicação, raramente conservado intacto nas viagens autor-ponto-ponto intérprete, intérprete público. ${ }^{16}$

Essa desqualificação do Martins Pena intelectual, em que os dramas ruins somam-se ao esteriotipado das suas personagens para configurar um quadro de ingenuidade e rala consistência estética, é exagerada e não parece captar a complexidade deste artista morto antes que, como pontuou Machado de Assis, pudesse "empreender obras de maior vulto". ${ }^{17} \mathrm{O}$ aspecto destacado por Jacobi da fugacidade daquele texto, no entanto, reforça a perspectiva de um Pena encenador, envolvido com a criação de espetáculos mais do que com uma produção literária. Se os dramas, inclusive, fossem pensados como projetos de encenação, mereceriam serem revistos não pelas suas qualidade literárias e mais como projeções de uma teatralidade grandiosa, cujo padrão, como se vem enfatizando, era o da ópera italiana.

Darcy Damasceno, cujo mérito na compilação e organização da obra de Martins Pena é inegável, também contribui no sentido desta percepção do processo criativo de Pena como dinâmico e distante do gabinete literário. Em 
artigo de $1954^{18}$ ele revela, com base nos manuscritos de Pena, todos os meandros da elaboração de O Juiz de Paz na Roça, desde a primeira versão em 1833, passando pela reelaboração do texto em 1837 e pelo texto da encenação de 1838, e chegando até um texto final na edição em livro de 1843. Tantas transformações mais do que burilamentos literários refletem, com certeza, as diversas montagens que o texto teve - duas em 1838, uma em 1840, e mais duas em 1841.

Concluindo esta revisão da fortuna crítica de Martins Pena, resta ver como os principais comentadores, que foram responsáveis pelo cânone estabelecido na academia em torno do escritor, lidaram com este aspecto material do seu teatro. Sílvio Romero valoriza mais a capacidade do cronista superficial de captar o ridículo de situações e transformá-las em risos fartos, mas não reconhece nele o "temperamento filosófico" que o fizesse tirar dessa investida sobre a realidade "uma conseqüência qualquer". Sobra-lhe, assim, a autenticidade de seus retratos que permitem a reconstituição da "fisonomia moral de toda essa época". ${ }^{19}$ José Veríssimo acompanha Romero no enfoque do elemento nacional do que prefere chamar de farsas, reconhecendo nelas "o meio brasileiro que lhes serviu de modelo e tema. E só talvez dela, em todo o nosso teatro, se poderá dizer a mesma coisa. ${ }^{.20}$ Ambos os autores pensam as peças de Pena, mesmo que reconhecidas como portadoras de uma qualidade perene e sempre representáveis, de um ponto de vista literário, ou, melhor ainda, como expressões de uma identidade nacional refletida na forma teatral. Este enfoque, pelo que contém de abstração, distancia o teatro de Pena de sua realidade objetiva de fenômeno teatral, atribuindo-lhe as virtudes da elaboração de uma dramaturgia de cunho nacional.

Tânia Brandão, em ensaio primoroso que faz um inventário aprofundado do cânone de Pena ${ }^{21}$, tenta desmontar esta perspectiva que nasce com Romero e Veríssimo, mas que reaparece em quase todos os comentadores posteriores. Formulando um olhar sobre o teatro a partir da noção de história cultural e literária, identifica nos conteúdos sociais e nacionais das comédias de Pena, que são valorizados por todos os críticos anteriores, nada mais do que uma expressão da ideologia do Estado brasileiro à época. Destaque-se a menção que faz ao ensaio de Bárbara Heliodora, sobre a evolução de Martins Pena do ponto de vista da técnica dramatúrgica ${ }^{22}$, como o único ponto de aproximação com uma perspectiva de análise dos aspectos materiais daquela produção. No geral, porém, Brandão atem-se aos aspectos conteudísticos que, se são fundamentais para pensar a obra de Martins Pena de um ponto de vista político e ideológico, 
pouco contribuem na reconstituição de sua efetiva materialidade.

Vale fazer uma última menção ao trabalho de Décio de Almeida Prado em torno do ator João Caetano. Sem dúvida, é um esforço monumental de reconstituição da teatralidade no Brasil do século 19, que inspira esta pesquisa. Há de se reconhecer, contudo, que o foco fechado em João Caetano desviou o olhar de Almeida Prado dos aspectos cênicos da obra de Pena, bem como das características materiais dos espetáculos transcorridos do Teatro São Pedro. Afastado do São Pedro por incompatibilidade com as rígidas normas disciplinares impostas pela administração do teatro na época, João Caetano sombreia, nos estudo de Almeida Prado, todos os eventos que ocorreram por lá na primeira metade da década de quarenta, particularmente a faceta cênica do teatro de Pena. A exceção a este desprezo pelos aspectos cênicos da produção de Martins Pena é o trabalho de Vilma Áreas, que aponta, no capítulo "Caixa de Cena" de sua investigação sobre os Folhetins ${ }^{23}$, a riqueza potencial de uma pesquisa que enveredasse por esse caminho.

Como se vê, a perspectiva de reconstituir a materialidade cênica do Teatro São Pedro, e de identificar os aspectos cênicos da obra de Martins Pena, resgatando inclusive a sua contribuição no estabelecimento de padrões locais na incorporação das técnicas cenográficas e cenotécnicas do teatro europeu, é tributária muito mais dos historiadores pioneiros do que das grandes análises que estabeleceram o cânone literário de Pena no país. O olhar que busca um Pena encenador vira de cabeça para baixo o baú de referências sobre o dramaturgo, e obriga ao reconhecimento de comentadores cujos trabalhos tinham sido colocados em segundo plano.

\section{Notas}

1 Da Veiga, Luiz Francisco, Luiz Carlos Martins Penna - o criador da Comédia Nacional Revista do Instituto Histórico Geográfico, IHGB, Rio de Janeiro, , vol.40, 1877, pp 375-95.

2 Jornal do Comércio, Rio de Janeiro, 15 de setembro de 1845.

3 Jornal do Comércio, Rio de Janeiro, 21 de setembro de 1845. Segundo Luiz Francisco da Veiga o texto de M.de La Clede citado pelo redator foi retirado "da tradução do lexicógrafo fluminense Antônio de Moares e Silva". Op.cit. p.391.

4 Da Veiga, Op.cit. p.398.

5 Magalhães Jr.,Raimundo, Martins Pena e Sua Época, São Paulo e Rio de Janeiro -LISA e INL-MEC, 1972.

6 P.cit, p.51.

7 op.cit. p.24.

${ }^{8}$ Jornal do Comércio, Rio de Janeiro, 5 de setembro de 1840.

9 Magalhães Jr. Op.cit.p37.

10Jornal do Comércio, Rio de Janeiro, 5 de setembro de 1840.

11 Magalães Jr., op.cit. pp35-7. 
12 Publicado no Suplemento do jornal O Estado de S.Paulo. 17 de agosto de 1954.

13 Op.cit.

14 Debret deixou o Brasil em 1831, depois de atuar não só como pintor de cenas pitorescas dos nosso costumes mas como cenógrafo, realizador de telões para ópera e tragédias.

15 É importante frisar o significado da palavra "pitoresca" (relativa a pintura). Ver ensaio de Luiz Felipe de Alencastro, “A Pena e o Pincel”, em Rio de Janeiro cdade mestiça, São Paulo, Companhia das Letras, 2001. 16 Suplemento Literário do Jornal Estado de S. Paulo, 17 de agosto de 1957.

17 Apud. Magalhães Jr. op.cit. pp.248-9

18 Damasceno, Darcy, A Elaboração de O Juiz de Paz na Roça, Revista do Livro, ${ }^{\circ} 1$, Rio de Janeiro, INL, ppp47-57. 1954.

19 Apud, Brandão Tânia, Martins Penna e a questão do teatro nacional, Monografias , Rio de Janeiro, Serviço Nacional do Teatro, 1979.pp.29-30

20 Idem.ibidem.p. 30

21 Brandão, Tânia, Op.cit..

22 Heliodora, Bárbara, A Evolução de Martins Pena, Dyonisos, Ano X, nº13, Rio de Janeiro, 1996.

23 Áreas, Vilma, Na Tapera de Santa Cruz : uma leitura de Martins Pena, São Paulo, Martins Fontes, 1987, pp.5-42. 